\title{
A Financial Perspective on Improving ICT Service Delivery: A Case at the Belgian Railways
}

\author{
Luc Lutin $^{1}$, Stijn Viaene ${ }^{1,2}$, Nathalie Demeere ${ }^{3}$, and Olivier Jolyon ${ }^{3}$ \\ ${ }^{1}$ Vlerick Business School, Vlamingenstraat 83, 3000 Leuven, Belgium \\ ${ }^{2}$ KU Leuven, Naamsestraat 69, 3000 Leuven, Belgium \\ ${ }^{3}$ Deloitte Consulting, Berkenlaan 8c, 1831 Diegem, Belgium \\ \{luc.lutin, stijn.viaene\}@vlerick.com, \\ \{ndemeere, ojolyon\} adeloitte.com
}

\begin{abstract}
This article discusses the financial perspective in a case study at ICTRA $^{1}$ that deals with improving ICT service delivery. It outlines the threestep approach taken in the Finance Transformation Project and explains how this approach helped ICTRA in becoming a more business-oriented ICT shared service centre.
\end{abstract}

Keywords: Finance, ICT, Transformation, Budgeting, Transfer Pricing, Service Costing, Service Levels.

\section{Introduction: Challenges and Strategic Intent}

This section zooms in on the external (market, evolution...) and internal (company vision, internal projects...) factors relevant to the context of the case study in this article.

\subsection{External Challenges}

Run as a government monopoly, $\mathrm{NMBS} \mathrm{SNCB}^{2}$, the national railway company of Belgium, was used to evolving at its own pace. With the upcoming liberalisation and privatisation of Europe's railway system, it needed to prepare for a more demanding environment. This required a clear strategy to cope with increased competition. The company would need to be able to respond more quickly and accurately to rapidly changing market demands. Internal reorganisation was therefore a must.

Consequently, in $2005 \mathrm{NMBS} / \mathrm{SNCB}$ was reorganized into three separate entities (see Fig. 1). The railway operator (NMBS/SNCB) would be responsible for freight

\footnotetext{
${ }^{1}$ This article was written as the basis for discussion, rather than to illustrate either effective or ineffective handling of a business situation.

2 The NMBS/SNCB was founded in 1926. NMBS/SNCB stands for "Nationale Maatschappij der Belgische Spoorwegen" (NMBS) in Dutch and "Société Nationale des Chemins de fer Belges" (SNCB) in French.
} 
and passenger services as well as the management of all rolling stock. Infrabel would be responsible for maintaining, renovating and developing the Belgian railway network infrastructure. NMBS/SNCB Holding, the umbrella organisation and owner of the operator NMBS/SNCB and Infrabel, would be responsible for asset management, human resources, strategy, finance and ICT. The above three entities together formed the Belgian Railways Group.

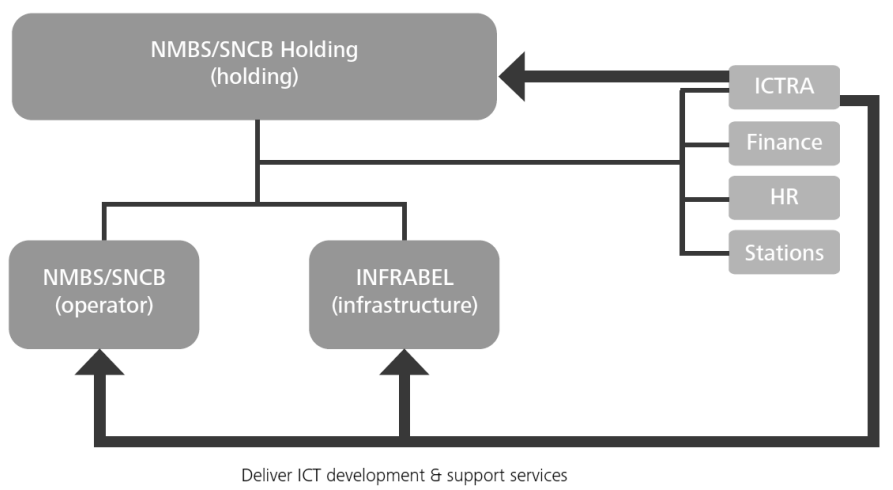

Fig. 1. Structure of the Belgian Railways Group since 2005 (situation 2010)

\subsection{Internal Challenges}

Following the reorganisation in 2005, ICTRA ${ }^{3}$, as a division of NMBS/SNCB Holding, became the preferred supplier of ICT services to the three business entities of the Belgian Railways Group (the Group). Its activities could be divided into three categories: (1) standard operational/supply activities, such as the ICT helpdesk and hardware support; (2) development and maintenance of applications, such as eticketing; and (3) implementation of strategic projects, e.g. real-time passenger information systems and ERP (Enterprise Resource Planning) applications.

Over the years, the Group's business entities grew dissatisfied with ICTRA's services as well as the transfer pricing mechanism. They felt ICTRA's services did not meet their needs. As for the budgets, they had the impression they were signing a blank cheque at the start of each financial year. Although the ICT budgets were discussed as part of the budget cycle, ICTRA charged actual costs with almost no explanation. The business wanted to be notified of changes and their impact on the actual budget in advance, instead of having to learn about them through the invoice. The business entities also wanted to have a say in the make-or-buy decision, i.e. in the choice between ICTRA and external service providers. This meant that they wanted ICTRA to submit a formal offer, detailing scope, timing and pricing. In short: the business entities wanted to be treated as a customer, receiving high-quality services at a fair price.

\footnotetext{
${ }^{3}$ ICTRA is short for Information and Communication Technology (ICT) for Rail. Operating as a shared services centre, it provides ICT development and support services to the entire Belgian Railways Group.
} 


\subsection{Strategic Intent}

In 2008, ICTRA formulated a new vision to address the external and internal challenges. As a support organisation, ICTRA wanted to be recognised for its strong technological know-how and experienced ICT employees. It would seek to continuously improve the productivity of its services, while matching supply to demand [1]. ICTRA therefore had to become a partner who understands the needs of the business. To ensure optimal delivery of business value, it would have to deliver total solutions, from development to utilisation.

\section{Transforming ICTRA}

\subsection{Starting from the Vision}

To achieve its vision, ICTRA embarked on a transformation path. At the heart of ICTRA's transformation was a fundamental review of its internal financial processes. In 2008, ICTRA launched its Finance Transformation Project. This project would help address the following major issues that had contributed to the dissatisfaction felt by ICTRA's internal customers:

- ICTRA's service catalogue was not aligned with the requirements of the business entities.

- ICTRA's services lacked the transparent pricing mechanisms of external providers.

- ICTRA's internal financial business processes were cumbersome, lacked structure and tools, and did not involve stakeholders sufficiently.

- There was an overall lack of cost awareness within the ICTRA organisation.

The Finance Transformation Project would increase operational process effectiveness in order to ensure a more customer-oriented service delivery [2]. It consisted of three phases: (1) establish commitment, (2) gain credibility and (3) prove competence. The project was led by Sammie Courtens, ICTRA's Head of Finance. Giovanni Palmieri, ICTRA's General Manager and Group CIO, was the project's sponsor.

\subsection{Adopting a New ICT Operating Model}

To support optimal delivery of business value, ICTRA adopted a new operating model, in parallel with the Finance Transformation Project. This target operating model clearly distinguished between demand-oriented and supply-oriented responsibilities. By adapting its organisation to this model, ICTRA would be able to put the right focus on the business. ICTRA therefore decided to migrate from a functional structure to a matrix organization (see Fig. 2.). This new organisational structure was designed to support business-oriented servicing and divided the ICTRA organisation in "shared operations supply units" on the one hand and "business entity solution units" on the other. These units would be supported by a number of "support departments", such as Finance. 


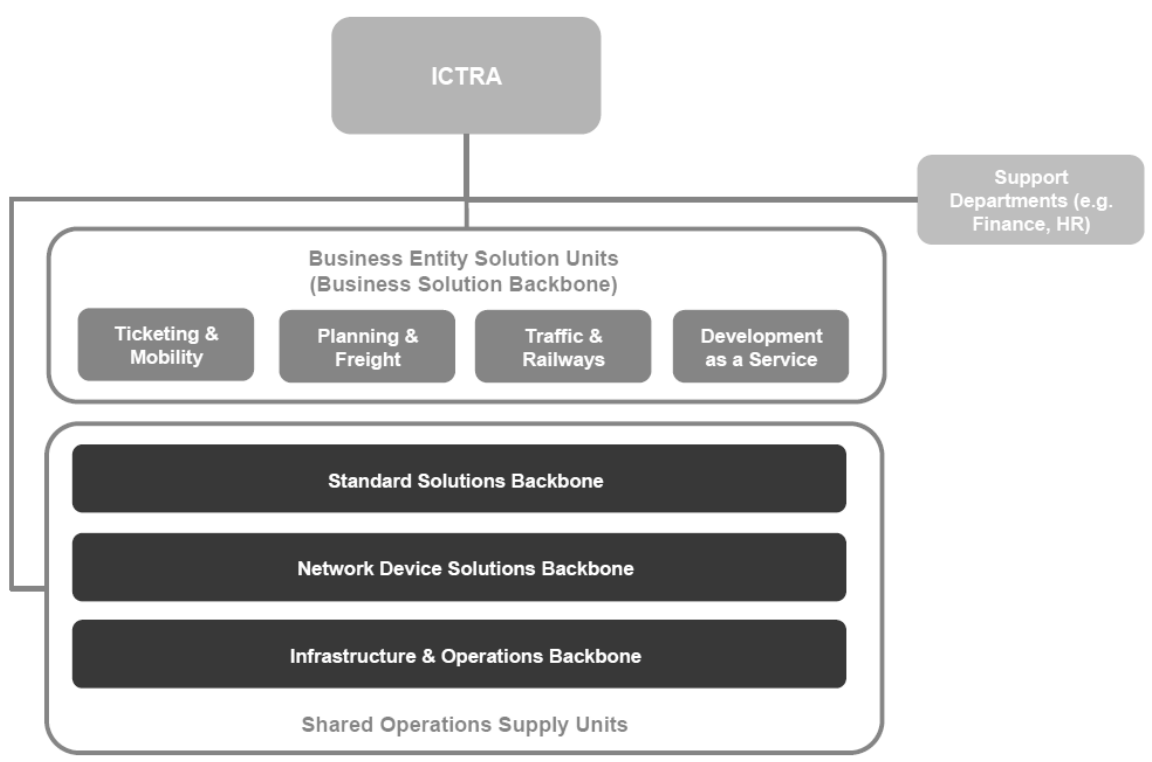

Fig. 2. New organizational structure

The shared operations supply units, or supply units, were structured around broad capabilities and transversal processes (network device \& solutions, infrastructure \& operations, and standard solutions). Their focus would be on cost efficiency and quality.

The business entity solution units, or demand units, were in charge of service and solution development for the respective Group business entities. These demand units were supported by account managers, performing a liaison role between ICTRA and the business. Together, they would drive process improvement and project design. Their aim was to be as close to the business as possible, increase ICT effectiveness and improve customer satisfaction.

\section{Finance Transformation Project}

The finance transformation and organisational restructuring went hand in hand with a formal change management (see Fig. 3.). This section outlines the three-step approach taken by ICTRA: 1) Establish Commitment, 2) Gain Credibility and 3) Prove Competence.

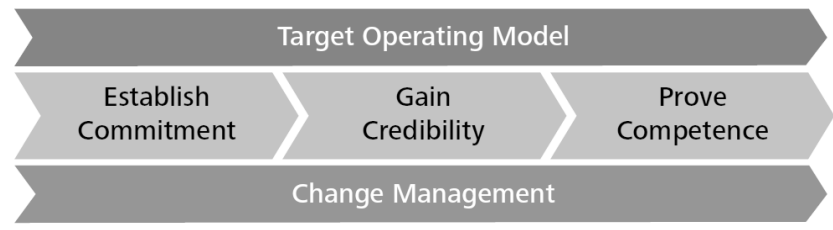

Fig. 3. Transforming ICTRA: building blocks 


\subsection{Establish Commitment}

Getting the business on board was essential to the success of the finance transformation. Therefore, ICTRA initiated discussions with the business entities of the Group, which resulted in the joint development of a business-specific service catalogue.

This catalogue then served as a basis for establishing service level agreements (SLAs) per service and per business entity. Service level negotiations between the business entities and ICTRA were guided by the following values: customer focus, appropriate level of detail, completeness of scope, clarity, and delivery credibility. SLAs would typically contain a detailed description of the services offered as well as a specification of the required service levels, a pricing per service item, and key performance indicators.

Business entities could choose their desired service levels. For example, a "gold package" for the ticketing machines would include 24-hour support, while a "bronze package", more appropriate for less critical applications, would only offer support during working hours.

It was also agreed that the pricing per service would be determined using a cost chargeback model (see next section). This model would enable ICTRA to accurately charge costs made for the delivery of its services to the consumers of these services, based on actual consumption.

When engaging with the business in this first phase, ICTRA was guided by the motto "Deliver what you promise". The collaborative development of the service catalogue and service level agreements was aimed at gaining the necessary commitment from all stakeholders - both ICTRA and the business.

\subsection{Gain Credibility}

To become a trusted business partner, ICTRA needed to determine a fair price for its services. Also, it had to communicate clearly and explain its invoices and any deviations from the budget to its customers, i.e. the business entities of the Group.

A key step in gaining credibility with the business was the development of the cost chargeback model [3]. This model would:

- make ICT costs more predictable and transparent as they would be based on the actual quantity of services delivered. Through the model ICTRA would also provide more details on the cost drivers of its services.

- increase cost awareness and help understand service profitability for the purpose of cost control.

- be benchmarked regularly with internal and external alternatives and offer the flexibility to change costing according to new business developments.

There are many ways to recoup the cost of delivering a service [4]. The approach followed by ICTRA was to first calculate the cost per service item ("service costing"), then set a service unit transfer price to cover the costs and stimulate desirable demand for their services, and finally multiply the unit price by the quantity of service 
delivered ("transfer pricing"). Then using the most appropriate transfer pricing strategy for ICTRA's services has allowed them to influence business decisions.

The steps of ICTRA's cost chargeback model are outlined in more detail in Fig. 4.

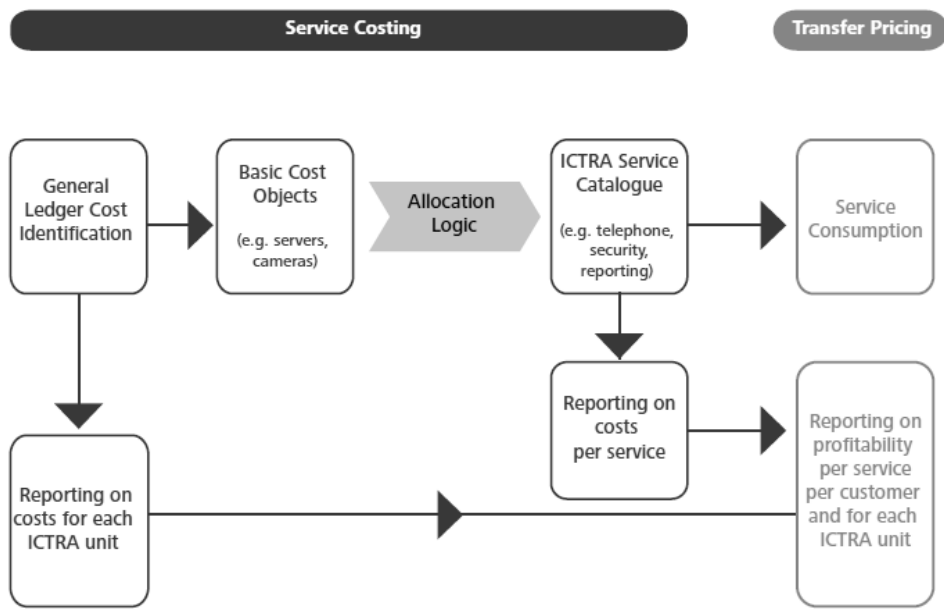

Fig. 4. Cost chargeback model

First, the costs identified in the "general ledger" were allocated to "basic cost objects" (e.g. servers, cameras, IP). These costs were then allocated to "ICTRA service catalogue items" (e.g. application hosting, connectivity, telephone, security, reporting) according to an allocation logic. The result was a service unit cost for each item in the service catalogue. The service unit transfer price resulted from adjusting the service unit cost according to four pricing strategy principles:

- Commercial strategy: transfer prices were compared with market prices and set competitively.

- Technological strategy: the use of technology supported by ICTRA was favoured in terms of transfer price. Unsupported technology, which would be more expensive to service, was penalised.

- Service level agreements: the difference in service levels (e.g. gold, silver and bronze) was reflected in the transfer price.

- Transfer pricing of prior years: to avoid excessive differences between the old transfer prices and transfer prices calculated with the new cost chargeback model, it was decided that transfer prices should only gradually change.

The cost chargeback model was developed, tested and fine-tuned iteratively by ICTRA and extensively explained to the Group's business entities. To support this effort, ICTRA's Finance department made sure to provide the necessary cost management training to ICTRA's non-financial staff. Not only did this improve the understanding of financial issues, it also helped to create a shared language, which in turn optimised the alignment of all parties involved. 
The cost chargeback model was also used for reporting: (1) on the cost of service delivery for each ICTRA supply and demand unit and (2) on the profitability per service, per ICTRA supply and demand unit and per customer (Group business entity).

\subsection{Prove Competence}

The ultimate test for the new cost chargeback model was whether it would survive the budget cycle.

The existing budgeting process had already caused a lot of frustration for the Group's business entities. ICT budgets only seemed to increase year after year and could not be questioned. The Group's business entities felt like signing a blank cheque, authorising ICTRA to spend without trying to improve its operating efficiency. Another cause of frustration was the time needed to determine the budget.

ICTRA had also identified inefficiencies in the existing budgeting process: it lacked formal guidelines, standard templates and definitions, as well as validation opportunities. Neither business requirements nor cost trend analyses were taken into account. From ICTRA's point of view, ICT budgets often seemed inconsistent and lacked ownership. To overcome these shortcomings, a new budgeting process was designed combining a top-down and a bottom-up approach. An innovation to ICTRA in this new budgeting process was the interaction between business and ICT to match their demand and supply planning and associated budgets. With the help of ICTRA's Finance department information processing was streamlined to enable a constructive dialogue.

Benefits of the new budgeting process included: (1) an improved financial accuracy and transparency. Budgets had become more predictable at the different levels as ICTRA's non-financial managers and the Group's business entity managers had improved their understanding of financial and service delivery concepts. (2) Credibility was no longer subjective but objective and quantifiable. Managers who were unable to adapt supply to demand would end up with non-rechargeable costs that they would have to explain to ICTRA's General Manager and ICTRA's Head of Finance. (3) The standardised budget cycle resulted in more reliable budget-setting. Because the jointly-developed service catalogue offered services responding to real business needs rather than standard services defined by ICTRA, the Group's business entities and ICTRA felt they were working as a team. The result: well thoughtthrough services and projects, and improved business satisfaction.

\section{Outcome and Conclusion}

ICTRA's Head of Finance, Sammie Courtens, concluded as follows: "With the help of this finance transformation ICTRA is now better prepared for the liberalised market. Our service catalogue has enabled us to map and understand our offering to the business. Managers at ICTRA's demand and supply units have changed their 
mind-set completely. Not only do they now understand the real business requirements for ICT, they also focus more on cost effectiveness and operational efficiency."

For other organisations facing a similar challenge, ICTRA's finance transformation can serve as a blueprint. The following highlights conclude the three-step approach.

1. Establish Commitment: start building your service catalogue and negotiate service levels early in the process. One single, all-encompassing service catalogue would be ideal, but if this is too ambitious, better leave it for later and start off with the services for which there is buy-in from the business.

2. Gain Credibility: use your cost insights to set your transfer prices and use it as a vehicle to steer business behaviour and to stimulate desired demand for ICT services.

3. Prove Competence: integrate your work of the previous step in your business and put it to the test of your business counterparts, not only to gain buy-in, but also to show what you are capable of offering.

Acknowledgments. The authors wish to thank Deloitte Consulting Belgium for the financial support to the research effort, as well as Mr Sammie Courtens and his ICTRA colleagues who participated in our case study research.

\section{References}

1. Mark, D., Rau, D.P.: Splitting demand from supply in IT. McKinsey on IT, 22-29 (2006)

2. Viaene, S., De Hertogh, S., Jolyon, O.: Engaging in Turbulent Times - Direction Setting for Business and IT Alignment. International Journal of IT/Business Alignment and Governance 2(1), 1-15 (2011)

3. Kaplan, R.S., Cooper, R.: Cost \& effect: using integrated cost systems to drive profitability and performance. Harvard Business Press (1998)

4. Drury, D.H.: Assessment of chargeback systems in IT management. Information Systems \& Operational Research 38, 293-313 (2000) 